\title{
The effect of leisure time physical activity on the risk of pre-eclampsia and gestational hypertension
}

\author{
SYLVIE MARCOUX, JACQUES BRISSON, AND JACQUELINE FABIA \\ From the Epidemiology Research Unit, Department of Social and Preventive Medicine, Laval University, Quebec, \\ Canada
}

\section{ABSTRACT}

Study objective: To assess the relation between leisure time physical activity (LTPA) during the first 20 weeks of pregnancy and the risk of developing pre-eclampsia and gestational hypertension.

Design: Case-control study carried out over a 28 month period with retrospective data collection. Setting: Six hospitals in Quebec City and four hospitals in Montreal.

Participants: 172 women with pre-eclampsia, 254 with gestational diabetes, 505 controls. All were primiparous, with no history of high blood pressure before pregnancy (unless due to oral contraceptive use), or during the first 20 weeks of gestation. Cases were defined using recognised criteria, and $97 \%$ of those eligible agreed to be interviewed. Controls delivered in same hospital immediately after cases and had no more than one reading of elevated blood pressure during pregnancy; $96 \%$ of those eligible agreed to be interviewed.

Measurements and main results: Participants were interviewed in hospital a few days after delivery using a questionnaire. Information was collected on type, frequency and average duration of any LTPA performed regularly during the first 20 weeks of pregnancy, together with medical, obstetric and sociodemographic details. It was found that women who performed regular LTPA had a reduced risk of pre-eclampsia (adjusted RR 0.67, 95\% CI 0.46-0.96) and gestational hypertension (aRR 0.75, $95 \%$ CI $0.54-1.05)$, and the relative risks decreased as the average time spent in LTPA increased (aRR for pre-eclampsia among women with low, moderate and high energy expenditure: 1.00, 0.77 and $0.57, \mathrm{p}=0.01)$. The same trend was present for gestational hypertension $(1.00,0.80$ and 0.71 , respectively, $\mathrm{p}=0.08$ ).

Conclusions: Leisure time physical activity during the first half of pregnancy is likely to reduce the risk of pre-eclampsia and gestational hypertension.

Vigorous exercise ${ }^{1}$ and physical fitness ${ }^{2}$ have been shown to reduce the incidence of hypertension in epidemiological cohort studies. To our knowledge, the relation between maternal physical activity and the development of pregnancy induced hypertension has not previously been assessed. Working in pregnancy does not seem to increase the risk of developing pregnancy induced hypertension. ${ }^{34}$ On the other hand, increased bedrest was reported to reduce the incidence of pregnancy induced hypertension in a group of 32 nulliparous women identified at high risk by the rollover test. ${ }^{5}$ Bedrest is still recommended in the treatment of pregnancy induced hypertension, ${ }^{6}$ although no beneficial effect of bedrest was demonstrated in Mathews' randomised controlled trial. $^{7}$

This case-control study was designed to evaluate the influence of personal characteristics and life style of mothers during the pregnancy on the risk of preeclampsia and gestational hypertension. We report here the effect of leisure time physical activity during the first 20 weeks of pregnancy on the risk of pre-eclampsia and gestational hypertension.

\section{Methods}

\section{CASES AND CONTROLS}

Cases and controls were women who delivered in six hospitals of the Quebec City area between April 1984 and December 1986, or in four Montreal hospitals between January and December 1986 . The study was restricted to primiparous women who had no history of high blood pressure before pregnancy (except if the high blood pressure was due to oral contraceptive use), and showed no sign of hypertension during the first $\mathbf{2 0}$ weeks of pregnancy. 
Cases were defined according to the criteria proposed by Davey and MacGillivray. ${ }^{8}$ Gestational hypertension corresponds to an elevation of diastolic blood pressure to $90 \mathrm{~mm} \mathrm{Hg}$ or more, on at least two consecutive occasions $4 \mathrm{~h}$ or more apart. The elevation of blood pressure must be observed after twenty weeks of gestation and not later than $24 \mathrm{~h}$ after delivery. Pre-eclampsia corresponds to hypertension, as defined above, associated with significant proteinuria. Significant proteinuria was considered present when one $24 \mathrm{~h}$ urine collection showed a total protein excretion of $300 \mathrm{mg}$ or more, or when two urine specimens collected $4 \mathrm{~h}$ or more apart showed protein equivalent to at least $1 \mathrm{~g}$ albumin/litre. Controls were women who delivered in the same hospitals as cases, whose deliveries followed immediately those of cases, and who had not more than one elevated blood pressure reading after 20 weeks of gestation.

\section{DATA COLLECTION}

Cases and controls were interviewed at the hospital a few days after delivery. Women were asked whether they had performed some leisure time physical activity (LTPA) regularly (at least once a month) during the first 20 weeks of pregnancy. If so, they had to specify for every activity performed the type, frequency and average duration on each occasion. The average time spent weekly in LTPAs in the year before pregnancy was also assessed. In addition, the questionnaire elicited information on maternal sociodemographic characteristics, personal and familial medical antecedents, reproductive and gynaecologic history, oral contraceptive use prior to pregnancy, height, pregravid weight and weight gain during pregnancy. Data were also obtained on consumption of cigarettes, drugs, vitamins, calcium, alcohol and caffeine during the first 20 weeks of pregnancy.

Medical records of all cases and controls were reviewed to ensure they met inclusion and exclusion criteria. When not available in the medical record, information on blood pressure readings at prenatal visits was obtained from the attending physician.

Agreement to be interviewed was obtained in $97 \%$ of eligible cases and $96 \%$ of eligible controls. The analyses were based on the remaining 172 women with pre-eclampsia (including 11 women with eclampsia), 254 with gestational hypertension and 505 controls.

\section{ANALYSIS}

An intensity code was assigned to each leisure time physical activity, using the list provided in the original Minnesota questionnaire, ${ }^{9}$ and revised by Folsom $e t$ $a l .{ }^{10}$ This code is an estimation of the energy (kcal/ min) required for the activity. Activities were considered light $(\leqslant 4 \mathrm{kcal} / \mathrm{min})$, moderate $(4 \cdot 1-5 \cdot 9$ $\mathrm{kcal} / \mathrm{min}$ ) or heavy ( $\geqslant 6.0 \mathrm{kcal} / \mathrm{min})$ according to the classification of Taylor et al. ${ }^{9}$ Examples of activities in each class are: light-walking for pleasure, bicycling, canoeing or rowing for pleasure; moderatebrisk walking, golf, home exercises, dancing, gardening; heavy-swimming, tennis, jogging, aerobics. The maximal intensity of LTPA performed by a subject was determined by the intensity level of the activity with the highest intensity code. Weekly energy expenditure in LTPA was obtained by multiplying the intensity code of each activity by its average duration (min/week), and by adding up all activities reported. Weekly energy expenditure in LTPA was categorised into low (no reported LTPA), moderate (1-840 kcal/week) and high (841 kcal/week or more). The cut off point for the last category corresponds to the median value of energy expenditure among active controls.

The odds ratios (OR) for pre-eclampsia and gestational hypertension were estimated by polychotomous logistic regression. ${ }^{11}$ This model yields adjusted ORs for pre-eclampsia than can be compared to those obtained for gestational hypertension. The OR is the ratio of the odds of performing LTPAs for cases to the same odds for controls. This exposure odds ratio provides an estimate of the relative risk (RR) since the diseases considered are relatively uncommon. ${ }^{12}$ Therefore, the terms relative risk and odds ratio will be used interchangeably.

Confidence intervals (CI) around ORs were calculated using the standard errors of the regression coefficients. Tests for trends in the ORs were performed to assess the presence of a dose-response. For each test, exposure status was defined in the logistic regression model by a single variable taking values corresponding to the categories of exposure (eg 1,2 or 3 for low, moderate or high energy expenditure respectively). The $\chi$ value corresponds to the ratio of the regression coefficient of this variable to its standard error. This allows testing for a linear increase of the $\ln (\mathrm{OR})$ across categories of exposure.

\section{Results}

Some characteristics of women with pre-eclampsia, gestational hypertension and controls are presented in table 1. Maternal age differed little between the three groups. Cases tended to be less educated and less physically active in the year before pregnancy than controls. The proportion of smokers was lower among cases than controls. Finally, cases had a higher baseline blood pressure, body mass index and weight gain during pregnancy.

Women who reported some LTPAs during the first 20 weeks of pregnancy had a lower risk of pre- 
Table 1 Distribution of cases and controls according to selected characteristics

\begin{tabular}{|c|c|c|c|}
\hline Characteristics & Pre-eclampsia & $\begin{array}{l}\text { Gestational } \\
\text { hypertension }\end{array}$ & Controls \\
\hline Maternal age (years), mean (SD) & $26 \cdot 0(4 \cdot 8)$ & $26 \cdot 2(4 \cdot 3)$ & $26 \cdot 1(4 \cdot 2)$ \\
\hline Education (years), mean (SD) & $12 \cdot 7(2 \cdot 6)$ & $12.9(2 \cdot 8)$ & $13 \cdot 1(2 \cdot 6)$ \\
\hline $\begin{array}{l}\text { LTPA in year before pregnancy (h/week), \% } \\
\qquad \begin{aligned} &< \\
& \geqslant 4 \\
& \geqslant 4\end{aligned}\end{array}$ & $\begin{array}{l}34 \cdot 1 \\
31 \cdot 8 \\
34 \cdot 1\end{array}$ & $\begin{array}{l}38 \cdot 6 \\
29 \cdot 5 \\
31 \cdot 9\end{array}$ & $\begin{array}{l}30 \cdot 8 \\
28 \cdot 8 \\
40 \cdot 5\end{array}$ \\
\hline $\begin{array}{l}\text { Number of cigarettes smoked at onset of pregnancy, \% } \\
0 \\
1-10 \\
11-20 \\
>20\end{array}$ & $\begin{array}{l}65 \cdot 1 \\
10 \cdot 5 \\
11 \cdot 0 \\
13 \cdot 4\end{array}$ & $\begin{array}{r}58 \cdot 7 \\
9 \cdot 8 \\
11 \cdot 8 \\
19 \cdot 7\end{array}$ & $\begin{array}{r}53 \cdot 3 \\
9 \cdot 7 \\
13 \cdot 5 \\
23 \cdot 6\end{array}$ \\
\hline $\begin{array}{l}\text { Maximal diastolic pressure in first } 20 \text { weeks of pregnancy }(\mathrm{mm} \mathrm{Hg}) \text {, } \\
\text { mean (SD) }\end{array}$ & $72 \cdot 4(8 \cdot 7)$ & $74.9(7 \cdot 5)$ & $70.5(8.6)$ \\
\hline Body mass index at onset of pregnancy $\left(\mathrm{kg} / \mathrm{m}^{2}\right)$, mean (SD) & $22.4(3.8)$ & $23 \cdot 1(4 \cdot 4)$ & $21 \cdot 0(2 \cdot 8)$ \\
\hline Weight gain (kg), mean (SD) & $15 \cdot 1(5 \cdot 4)$ & $16 \cdot 1(5 \cdot 3)$ & $13.7(4.2)$ \\
\hline
\end{tabular}

eclampsia and gestational hypertension than women who reported no LTPA (table 2). For both groups of cases, the relative risk decreased as the average number of hours spent weekly in LTPA increased. The trend was statistically significant for pre-eclampsia $(p=0.03)$ but not for gestational hypertension $(p=0 \cdot 12)$. While the relative risk of pre-eclampsia was inversely related to the maximal intensity of LTPA, relative risk of gestational hypertension showed little or no variation with the maximal intensity of LTPA. The protective effect of LTPA was observed when LTPA was expressed in terms of energy expenditure. Relative risks of pre-eclampsia and gestational hypertension decreased with increased weekly energy expenditure in LTPA. This trend was statistically significant for pre-eclampsia $(p=0.01)$. Among women in the highest category of energy expenditure, risk of pre-eclampsia and gestational hypertension

Table 2 Relative risks of pre-eclampsia and gestational hypertension according to time spent in LTPA, maximal intensity of LTPA and energy expended weekly in LTPA during the first 20 weeks of pregnancy

\begin{tabular}{|c|c|c|c|c|c|c|c|}
\hline \multirow[b]{2}{*}{ LTPA during the first 20 weeks of pregnancy } & \multicolumn{3}{|c|}{ Pre-eclampsia } & \multicolumn{3}{|c|}{ Gestational hypertension } & \multirow{2}{*}{$\begin{array}{l}\text { Controls } \\
n\end{array}$} \\
\hline & $n$ & $\boldsymbol{R} \boldsymbol{R}$ & $95 \% C I$ & $n$ & $\boldsymbol{R} \boldsymbol{R}$ & $95 \% C I$ & \\
\hline \multicolumn{8}{|l|}{ LTPA } \\
\hline $\begin{array}{l}\text { None* } \\
\text { Some }\end{array}$ & $\begin{array}{r}68 \\
104\end{array}$ & $\begin{array}{l}1.00 \\
0.67\end{array}$ & $0.46-0.96$ & $\begin{array}{r}92 \\
159\end{array}$ & $\begin{array}{l}1.00 \\
0.75\end{array}$ & $0.54-1.05$ & $\begin{array}{l}155 \\
350\end{array}$ \\
\hline \multicolumn{8}{|l|}{ Time spent in LTPA (h/week) } \\
\hline $\begin{aligned} & 0 \\
< & 4 \\
\geqslant & 4\end{aligned}$ & $\begin{array}{l}68 \\
63 \\
41\end{array}$ & $\begin{array}{l}1.00 \\
0.72 \\
0.60\end{array}$ & $\begin{array}{l}0.48-1.07 \\
0.38-0.95\end{array}$ & $\begin{array}{l}92 \\
91 \\
68\end{array}$ & $\begin{array}{l}1.00 \\
0.77 \\
0.73\end{array}$ & $\begin{array}{l}0.53-1.11 \\
0.49-1.09\end{array}$ & $\begin{array}{l}155 \\
201 \\
149\end{array}$ \\
\hline$\chi$-trend, $\mathrm{p}$ value & & $-2 \cdot 23$ & 0.03 & & $-1 \cdot 57$ & 0.12 & \\
\hline \multicolumn{8}{|l|}{ Maximal intensity of LTPA } \\
\hline $\begin{array}{l}\text { No LTPA* } \\
\text { Light } \\
\text { Moderate } \\
\text { Heavy }\end{array}$ & $\begin{array}{l}68 \\
46 \\
20 \\
38\end{array}$ & $\begin{array}{l}1.00 \\
0.82 \\
0.71 \\
0.53\end{array}$ & $\begin{array}{l}0.53-1.29 \\
0.40-1.28 \\
0.34-0.84\end{array}$ & $\begin{array}{l}92 \\
61 \\
28 \\
70\end{array}$ & $\begin{array}{l}1.00 \\
0.79 \\
0.74 \\
0.73\end{array}$ & $\begin{array}{l}0.54-1.25 \\
0.43-1.25 \\
0.50-1.09\end{array}$ & $\begin{array}{r}155 \\
125 \\
60 \\
165\end{array}$ \\
\hline$\chi$-trend, $p$ value & & $-2 \cdot 74$ & 0.006 & & $-1 \cdot 55$ & $0 \cdot 12$ & \\
\hline \multicolumn{8}{|l|}{ Energy expenditure in LTPA } \\
\hline $\begin{array}{l}\text { Low" } \\
\text { Moderate } \\
\text { High }\end{array}$ & $\begin{array}{l}68 \\
58 \\
46\end{array}$ & $\begin{array}{l}1.00 \\
r 77 \\
0.57\end{array}$ & $\begin{array}{l}0.50-1 \cdot 16 \\
0.37-0.89\end{array}$ & $\begin{array}{l}92 \\
81 \\
78\end{array}$ & $\begin{array}{l}1.00 \\
0.80 \\
0.71\end{array}$ & $\begin{array}{l}0.55-1.17 \\
0.48-1.04\end{array}$ & $\begin{array}{l}155 \\
175 \\
175\end{array}$ \\
\hline$\chi$-trend, $p$ value & & $-2 \cdot 50$ & 0.01 & & $-1 \cdot 77$ & 0.08 & \\
\hline
\end{tabular}

$\mathrm{n}=$ number of cases; $\mathbf{R R}=$ relative risk; $\mathbf{C I}=$ confidence interval; $\mathrm{LTPA}=$ leisure time physical activity

All relative risks are adjusted for body mass index

Three cases with gestational hypertension are excluded because of missing information on body mass index

- Reference category 
were respectively $43 \%$ and $29 \%$ lower than women who reported no LTPA. All relative risks presented are adjusted for body mass index. Further adjustment for variables shown in table 1 , including number of cigarettes smoked daily, did not change these relative risks.

Table 3 shows the effect of occupational activity during a regular working day in the first 20 weeks of pregnancy. For women with paid occupation, this refers to physical activity at work and for unemployed women, to physical activity at home. Frequent walking significantly reduced the risk of preeclampsia. The risk of pre-eclampsia also tended to decrease as the number of hours per day spent in standing position increased, but the trend was not statistically significant $(p=0 \cdot 11)$. On the other hand, neither frequent walking nor standing for long hours was related to the risk of gestational hypertension. Adjustment for energy expenditure in LTPAs in addition to body mass index did not change any of these relationships.

Finally, relative risks for time spent in LTPAs, maximal intensity of LTPA and energy expenditure in LTPAs were adjusted for body mass index and variables shown in table 3 simultaneously. Adjustment for physical activity during regular occupation had no effect on the relation between LTPA and the risk of pregnancy induced hypertension.

\section{Discussion}

These results suggest that women who perform leisure time physical activities during the first 20 weeks of their pregnancy may be at lower risk of developing pre-eclampsia or gestational hypertension. In 1962,
Erdelyi, in a survey of gynaecological problems of female athletes, mentioned an incidence of toxaemia of $2.2 \%$ in 172 athletes compared to $4.4 \%$ in a control group of non-athletes. ${ }^{13}$ Unfortunately, criteria for inclusion in the study groups were not given, type and intensity of physical activities performed were not described, toxaemia was not defined and potential confounding variables were not taken into account. To our knowledge, there is not other report on the relation of physical activity to pregnancy induced hypertension.

In our study, assessment of physical activity relied on a recall questionnaire. This constitutes the most practical and widely used approach for epidemiologic studies. ${ }^{14}$ Women were questioned on their activities during the first 20 weeks of pregnancy. This period precedes any clinical manifestation of pregnancy induced hypertension so that cases were no more likely than controls to have reduced their activities because of their condition. However, some errors of recall on frequency and duration of activities are likely to have occurred. If, as expected, the recall of cases was as good or better than the recall of controls, the observed protective effect of LTPA on pregnancy induced hypertension would have been underestimated and the true effect might in fact be stronger than the one we found. In addition, the association between LTPA and pregnancy induced hypertension cannot be explained by maternal age, education, cigarette consumption, baseline blood pressure, body mass index or weight gain as these variables were taken into account in the estimation of the relative risks.

We evaluated the effect of LTPA during the first 20 weeks of pregnancy on the risk of pregnancy induced hypertension. However, this effect is difficult to

Table 3 Relative risks of pre-eclampsia and gestational hypertension according to physical activity in regular work

\begin{tabular}{|c|c|c|c|c|c|c|c|}
\hline \multirow[b]{2}{*}{ Physical activity in regular work } & \multicolumn{3}{|c|}{ Pre-eclampsia } & \multicolumn{3}{|c|}{ Gestational hypertension } & \multirow{2}{*}{ Controls } \\
\hline & $n$ & $\boldsymbol{R} \boldsymbol{R}$ & $95 \% C I$ & $n$ & $\boldsymbol{R} \boldsymbol{R}$ & $95 \% \mathrm{CI}$ & \\
\hline \multicolumn{8}{|l|}{ Paid occupation } \\
\hline $\begin{array}{l}\text { No* } \\
\text { Yes }\end{array}$ & $\begin{array}{r}43 \\
129\end{array}$ & $\begin{array}{l}1.00 \\
0.80\end{array}$ & $0.52-1.21$ & $\begin{array}{r}49 \\
202\end{array}$ & $\begin{array}{l}1.00 \\
1 \cdot 16\end{array}$ & $0 \cdot 78-1 \cdot 73$ & $\begin{array}{l}100 \\
405\end{array}$ \\
\hline \multicolumn{8}{|l|}{ Walking } \\
\hline $\begin{array}{l}\text { Not frequent* } \\
\text { Frequent }\end{array}$ & $\begin{array}{r}61 \\
111\end{array}$ & $\begin{array}{l}1.00 \\
0.61\end{array}$ & $0.42-0.89$ & $\begin{array}{r}68 \\
183\end{array}$ & $\begin{array}{l}1.00 \\
0.90\end{array}$ & $0.63-1 \cdot 28$ & $\begin{array}{l}126 \\
378\end{array}$ \\
\hline \multicolumn{8}{|l|}{ Standing position (h/day) } \\
\hline $\begin{array}{l}<6.0^{\circ} \\
6.0-8.9 \\
\geqslant 9.0\end{array}$ & $\begin{array}{l}51 \\
73 \\
44\end{array}$ & $\begin{array}{l}1.00 \\
0.81 \\
0.68\end{array}$ & $\begin{array}{l}0.53-1.24 \\
0.43-1.09\end{array}$ & $\begin{array}{r}59 \\
113 \\
77\end{array}$ & $\begin{array}{l}1.00 \\
1.05 \\
1.03\end{array}$ & $\begin{array}{l}0.71-1.56 \\
0.68-1.58\end{array}$ & $\begin{array}{l}126 \\
212 \\
163\end{array}$ \\
\hline$\chi$-trend, $\mathrm{p}$ value & & $-1 \cdot 60$ & 0.11 & & $-0 \cdot 14$ & 0.89 & \\
\hline
\end{tabular}

See table 2 for abbreviations

All relative risks are adjusted for body mass index

Some totals may differ from table 2 because of missing values

* Reference category 
separate from that of LTPA prior to pregnancy. The two factors are highly correlated. ${ }^{15}$ In addition, LTPA prior to pregnancy was only assessed in terms of average weekly duration of activities and thus complete adjustment for physical fitness at the beginning of pregnancy may not have been achieved. ${ }^{16}$

Our assessment of physical activity focused mainly on physical activities during leisure time. Most modern occupations require little physical activity. Variability of physical activity at work is generally considered to be low. ${ }^{17}$ For these reasons, occupational activity may be regarded as relatively marginal in comparison with leisure time physical activities. Nevertheless, frequent walking or standing during working hours appeared to be related to a reduced risk of pre-eclampsia, a result consistent with the observed effects of LTPA.

The protective effect of leisure time physical activity on the development of pregnancy induced hypertension could be mediated through prostanoids. Exercise training can increase plasma prostacyclin and decrease serum thromboxane concentration. ${ }^{18}$ Prostacyclin is a potent vasodilator and inhibitor of platelet aggregation while thromboxane is a vasoconstrictor and stimulator of platelet aggregation. An imbalance in the opposing actions of prostacyclin and thromboxane has been implicated in the pathophysiology of pre-eclampsia, ${ }^{19}$ secondary to deficiency in prostacyclin and/or overproduction of thromboxane. ${ }^{20}$

Our results suggest that among women with normal blood pressure in the first 20 weeks of pregnancy, those physically active in early pregnancy might be at lower risk of developing hypertension later in pregnancy. They also provide some support for the present recommendations ${ }^{21}$ that low risk pregnant women can maintain their physical activities during pregnancy.

This work was supported by a research grant from the National Health and Research Development Program (NHRDP) of Health and Welfare Canada and a core grant from the Fonds de la Recherche en Santé du Québec (FRSQ). This research was done while S Marcoux was the recipient of a PhD fellowship from the FRSQ. J Brisson is a National Health Research Scholar of the NHRDP.

We wish to thank the obstetrician-gynaecologists and staff of the obstetrics departments of the participating hospitals: Christ-Roi, Enfant-Jésus, Hôtel-Dieu de Lévis, Jeffery Hale, Maisonneuve-Rosemont, NotreDame, Saint-François d'Assise, Saint-Sacrement, Saint-Luc and Sainte-Justine. We are also grateful to Suzanne Leblanc, Aline Pelletier and Nicole Meunier for assistance in data collection, and to Suzanne Brisson for computer programming.

Address for correspondence and reprints: Dr S Marcoux, Epidemiology Research Unit, Department of Social and Preventive Medicine, Faculty of Medicine, Laval University, Sainte-Foy, Qc, Canada G1K 7 P4.

\section{References}

' Paffenbarger RS, Wing AL, Hyde RT, Jung DL. Physical activity and incidence of hypertension in college alumni. Am J Epidemiol 1983; 117: 245-57.

2 Blair SN, Goodyear NN, Gibbons LW, Cooper KH. Physical fitness and incidence of hypertension in healthy normotensive men and women. JAMA 1984; 242: 487-90.

${ }^{3}$ Peters TJ, Adelstein P, Golding J, Butler NR. The effects of work in pregnancy: short- and long-term associations. In: Chamberlain G, ed. Pregnant women at work. London: Royal Society of Medicine and Macmillan Press Ltd, 1984: 87-104.

${ }^{4}$ Stewart A. A note on the obstetric effects of work during pregnancy. Br J Prev Soc Med 1955; 9: 159-61.

${ }^{5}$ Spinapolice RX, Feld S, Harrigan JT. Effective prevention of gestational hypertension in nulliparous women at high risk as identified by the roll over test. Am JObstet Gynecol 1983; 146: 166-8.

${ }^{6}$ Pritchard JA, Macdonald PC. Williams Obstetrics. 16th ed. New York: Appleton-Century-Crofts, 1980: 318.

${ }^{7}$ Mathews DD. A randomized controlled trial of bed rest and sedation or normal activity and non-sedation in the management of non-albuminuric hypertension in late pregnancy. Brit J Obstet Gynaecol 1977; 84: 108-14.

${ }^{8}$ Davey DA, MacGillivray I. The classification and definition of the hypertensive disorders of pregnancy. Clin Exp Hypertens Part B: Hypertension in pregnancy 1986; 5: 97-133.

9 Taylor HL, Jacobs DR, Schucker B, Knudsen J, Leon AS, DeBacker G. A questionnaire for the assessment of leisure time physical activities. J Chron Dis 1978; 31: 741-55.

${ }^{10}$ Folsom AR, Caspersen CJ, Taylor HL, et al. Leisure time physical activity and its relationship to coronary risk factors in a population-based sample. The Minnesota heart survey. Am J Epidemiol 1985; 121: 570-9.

${ }^{11}$ Dubin N, Pasternack BS. Risk assessment for case-control subgroups by polychotomous logistic regression. Am J Epidemiol 1986; 123: 1101-17.

12 Miettinen OS. Estimability and estimation in case-referent studies. Am J Epidemiol 1976; 103: 226-35.

13 Erdelyi GJ. Gynecological survey of female athletes. $J$ Sports Med Phys Fitness 1962; 2: 174-9.

14 Washburn RA, Montoye HJ. The assessment of physical activity by questionnaire. Am $J$ Epidemiol 1986; 123: 563-76.

${ }^{15}$ McGee D, Reed D, Yano K. The results of logistic analyses when the variables are highly correlated: an empirical example using diet on CHD incidence. J Chronic Dis 1984; 37: 713-9.

$16 \mathrm{Greenland} \mathrm{S}$. The effect of misclassification in the presence of covariates. Am J Epidemiol 1980; 112: 564-9.

${ }^{17}$ Laporte RE, Montoye HJ, Caspersen CJ. Assessmer physical activity in epidemiologic research: problems. prospects. Public Health Rep 1985; 100: 131-46. 
${ }^{18}$ Rauramaa R, Salonen JT, Kukkonen-Harjula K, et al. Effects of mild physical exercise on serum lipoproteins and metabolites of arachidonic acid: a controlled randomised trial in middle aged men. $\mathrm{Br}$ Med $J$ 1984; 288: 603-6. ${ }^{19}$ Walsh SW. Pre-eclampsia: an imbalance in placental prostacyclin and thromboxane production. $\mathrm{Am}$ J Obstet Gynecol 1985; 152: 335-40.
${ }^{20}$ Ylikorkala O, Makila U-M. Prostacyclin and thromboxane in gynecology and obstetrics. Am J Obstet Gynecol 1985; 152: 318-29.

${ }^{21}$ Pritchard JA, Macdonald PC. Williams Obstetrics. 16th ed. New York: Appleton-Century-Crofts, 1980: 681-2. Accepted for publication November 1988 